\title{
La trata de personas y la respuesta judicial
}

Trafficking in persons and the judicial response

Tráfico de pessoas e a resposta judicial

\author{
Mag. Aldo Gustavo Rengifo Kahn \\ rengifokahn@gmail.com \\ Universidad Nacional Amazónica de Madre de Dios \\ https://orcid.org/0000-0002-5182-0338
}

\section{RESUMEN}

La trata de personas es un delito reprimido por la legislación penal previo un proceso judicial consiste en abusar o maltratar una persona mediante el engaño u otros, sea captando, trasladando, reteniendo u otros con fines de explotación sea sexual o laboral, el perfil de trata de personas es en cantinas con damas de compañía en la Pampa. El objetivo de la investigación fue describir cual es la respuesta judicial en Tampobata- Madre de Dios desde el 2019 al 2021, el enfoque es cualitativo, el método que se utilizo fue la revisión documentaria de dictámenes fiscales y de resoluciones judiciales y entrevistas a los agentes involucrados como efectivos policiales de trata de personas, abogados litigantes, fiscales especializados, jueces y defensores de víctimas. El resultado fue por distintos motivos, la denuncia por trata mayormente termina en una disposición de archivamiento, en resolución de archivamiento o en una sentencia absolutoria.

Palabras claves: Trata de personas, fiscalía, poder judicial, resoluciones.

\begin{abstract}
Trafficking in persons is a crime repressed by criminal legislation prior to a judicial process consists of abusing or mistreating a person through deception or others, be it capturing, transferring, retaining or others for the purpose of sexual or labor exploitation, the trafficking profile of people is in canteens with company ladies in the Pampas. The objective of the research was to describe what the judicial response is in Tambopata- Madre de Dios from 2019 to 2021, the approach is qualitative, the method used was the documentary review of fiscal opinions and judicial resolutions and interviews with the agents. involved as human trafficking police officers, trial lawyers, specialized prosecutors, judges, and victim advocates. The result was for different reasons, the complaint for trafficking mostly ends in an archiving order, in an archiving resolution or in an acquittal sentence.
\end{abstract}

Keywords: Human trafficking, prosecution, judiciary, resolutions.

\section{RESUMO}

O tráfico de pessoas é crime reprimido pela legislação penal anterior ao processo judicial, consiste em abusar ou maltratar uma pessoa por meio de dolo ou outros, seja capturando, transferindo, retendo ou outros para fins de exploração sexual ou laboral, o perfil do tráfico de pessoas está em cantinas com senhoras de companhia nos Pampas. O objetivo da pesquisa foi descrever qual é a resposta judicial em Tampobata- Madre de Dios no período de 2019 a 2021, a abordagem é qualitativa, o método utilizado foi a revisão documental de pareceres fiscais e resoluções judiciais e entrevistas com os agentes envolvidos. policiais de tráfico de seres humanos, advogados de julgamento, promotores especializados, juízes e defensores das vítimas. O resultado foi por diferentes razões, a denúncia por tráfico termina em sua maioria em uma ordem de arquivamento, em uma resolução de arquivamento ou em uma sentença de absolvição.

Palavras-chave: Tráfico de pessoas, acusação, judiciário, resoluções.

\section{INTRODUCCION:}

La trata de personas es un delito protegido por normas jurídicas, este delito consiste La captación, el transporte, el traslado, la acogida o a recepción de personas, recurriendo a la amenaza o al uso de la fuerza u otras formas de coacción, al rapto, al fraude, al engaño, al abuso de poder, o de una situación de vulnerabilidad o a la concesión o recepción de pagos o beneficios para obtener el consentimiento de una persona que tenga autoridad sobre otra, con fines de explotación, conforme la definición del "Protocolo de las Naciones Unidas para prevenir, reprimir, y sancionar la trata de personas, especialmente mujeres y niños"; en la provincia de Tambopata del departamento de 
Madre de Dios, ubicado en el sur del Perú, es una llanura amazónica, selva cálida, capital de la biodiversidad, posee paisajes naturales, pero también es cierto que por otro lado tiene oro, siendo una de las actividades principales del departamento la actividad minera, y esta actividad atrae otras actividades legales e ilegales entre ellos la trata de personas y es de preocupación del Estado Peruano, con la construcción dela carretera interoceánica el 2010 es fácil el acceso de personas de cualquier departamento, como también de Brasil y de Bolivia, en ese contexto, es un tema importante es la trata de personas e incluso reportado en la prensa nacional, junto al tema de la minería ilegal del Sector de la Pampa, pero precisamente este hecho genera investigaciones fiscales , se da la intervención policial y fiscal, pero resulta más adelante en la misma fiscalía, o en el juzgado se da una suerte de perdida de la persecución se aplaza, pasan los meses o años, y va terminando en un archivamiento fiscal o judicial,y en una sentencia absolutoria, rara vez termina en una sentencia condenatoria aquí hay un problema que está pasando con las investigaciones fiscales o con los procesos penales, quien está fallando? las mismas personas víctimas no ponen su voluntad, no hay pruebas de cargos, , interpretación errónea, desconocimiento, o demasiada teoría pomposa subjetiva de trata de personas que no aterriza en la realidad. Me pregunto es una mito o realidad, porque esta diferencia entre el inicio del hecho denunciado y el final del hecho denunciado, justamente este estudio consistió en la descripción, comprensión, análisis de todo es camino entre el hecho de la denuncia o intervención policial, el tramite en el ministerio publico y en el poder judicial. Sobre trata de personas conocemos en las normas, en los libros, en los eventos académicos, sobredimensionado cifras, de protección a la libertad, a la dignidad, pero no se conoce en la realidad, en la praxis judicial.

\section{MARCO TEORICO:}

Según la Oficina de las Naciones Unidas contra la Droga y el Delito- UNOCD (2019), en el módulo nueve - respuesta de la justicia penal a la trata de personas indico que existen dificultades en las investigaciones y procesamiento por la falta voluntad de las victimas para declarar en contra de sus tratantes por temor, miedo, trauma ocasionado por la misma trata, señalaron también a la aplicación corrupta de la ley, falta de recursos de instituciones involucradas, una pequeña proporción de delincuentes de trata de personas es procesado cada año. Según Abdulkareem, SH (2021), menciono que las mujeres aspirando tener una mejor vida terminan siendo victimas de trata de personas en esa línea según, Alarcón (2018), menciono que la actividad minera trae como delito conexo a la trata de personas, en ese orden de ideas Arana, E (2015) señalo que la trata de personas es un abuso en donde se cosifica a la persona como un simple objeto. Sin embargo, Barbuzano et al., (2020), nos afirmo que las mujeres nigerianas son víctimas de explotación sexual, en ese sentido Dammert (2020), dijo que la trata de personas ataca la dignidad y libertad, pero es poca estudiada. Defensoría del Pueblo (2018), mostro su preocupación por las sentencias absolutorias y recomendó que la Policía tenga un registro de víctimas, y que la fiscalía trabaje coordinadamente con la policía y UDAVIT, por otro lado, Diaz (2017) aludió que se exploro un análisis critico de la trata de personas. Fuentes (2018), concluyo que Madre de Dios siendo una región golpeada por actividades ilegales entre ellos la trata de personas a logrado superponerse, en cambio Hatfield (2018) en su estudio mencionó el tema de la trata de personas es un problema de magnitud global que no discrimina entre edad, sexo o estatus social, en otra idea, Jaimes et al (2018) que en la lucha contra la trata no hay resultados concretos. Por otro según Jaris (2016) afirmo que la trata de personas en Ucayali es por el trabajo de la madera. En forma particular Ordinola (2019) hizo un análisis critico a la sentencia del caso Elsa Cjuno que resolvieron no haber nulidad de la sentencia absolutoria; sin embargo, Pajon, (2020), señalo que la trata de personas es difícil de probar; y Rodríguez \& Ramos (2018), destaco los nudos mas críticos de la trata y el rol de las autoridades. (Tuesta, 2018) dijo que la literatura es escasa y fiscalía selecciona los casos. Vargas et al (2019) señalo que la trata de 
personas debe monitorearse y aplicar con estrategia. Sin embargo, Alarcón, (2018) en su investigación, afirmó que la minería ilegal en Madre de Dios trae como consecuencia delitos como el delito de trata de personas. Por otro lado, Blanco \& Marinelli (2017) en su estudio en la PUCP, señalaron que se debedar un enfoque de derechos humanos a las víctimas de trata de personas, y que se debe perfeccionar para que el aparato estatal tenga una verdadera lucha contra la trata de personas. Según Capcha (2018) en su tesis en la UCV sobre trata de personas menciono que le dio un enfoque interpretativo, y enfoque cualitativo, para describir y llegar a una comprensión, el diseño fue fenomenológico, la muestra estuvo con 9 entrevistados, concluyendo que somos un pais informal se reduce el riesgo en la comisión del delito porque no hay control y alta tolerancia social , concluyendo que la violencia física y psicología es uno es una de las formas habituales de llevar a cabo la trata de personas. INEI, (2019) concluye que las estadísticas van en aumento por el delito de trata de personas, y este es un hecho mundial que afecta los derechos humanos. Asimismo, CHS alternativo, (2014) nos dijo que la trata de personas es una de las expresiones mas extremas de la violencia convertida la victima en presa de sus intereses. En ese orden de ideas, Montoya (2016) afirmo que el delito de trata de personas es un delito complejo, y presenta dificultades en la jurisprudencia peruana.

\section{METODOLOGIAS Y MATERIALES:}

Esta investigación se utilizó el enfoque cualitativo, teniendo como antecedente en Panamá a Zhulali de Andrés (2017), en su tesis doctoral enfatizó el enfoque cualitativo en su investigación de trata de personas. La revisión documentaria consistente en disposiciones fiscales y resoluciones judiciales, es de tipo básico, descriptivo, inductivo, diseño fenomenológico, así como también de entrevistas a profundidad a los involucrados, 3 abogados litigantes, 1 fiscal, 1 juez, 1 defensor de víctimas, 1 investigado por trata de personas, 1 efectivo de la PNP de trata de personas, 1 victima dama mayor de edad. En el estudio no hubo conflicto de intereses en las entrevistas, se declaró sobre casos judiciales ya resueltos con autoridad de cosa juzgada; y respecto a las entrevistas, los entrevistados declararon en plena libertad, capacidad, conocimiento y con el consentimiento informado tratándose del fiscal y del juez se guardo la confidencia de su nombre a su pedido.

\section{RESULTADOS}

Este estudio producto de las revisión de los dictámenes fiscales y de las resoluciones judiciales de los años 2019, 2020 y 2021 y de las entrevistas a profundidad, se encontró hallazgos comunes en los expedientes penales, como que el hecho denunciado por trata de personas con intervención policial en los bares con damas de compañía y con detención hasta por 48 horas máximo a las personas encontradas en el lugar como el cajero, encargado, administrador, dueño, seguridad, mozo, entre otros, e incluso en custodia algunas presuntas victimas e incluso extendido a la publicidad de la prensa local, regional o nacional , al inicio e incluso hasta el juzgado da prisión preventiva a los intervenidos por 9 meses a requerimiento de fiscalía, pero resulta que con el transcurrir de los días, semanas, meses y años va perdiendo vigor, trascendencia, atención por los actores y entidades involucradas y en la búsqueda de pruebas el ministerio publico va reuniendo pruebas que no necesariamente son de cargos, posteriormente salen en libertad de acuerdo a ley, y va terminado con auto de archivamiento o sentencia absolutoria; la dama de compañía indico que ella llego a trabajar en el bar por invitación de una amiga, con su voluntad que nadie lo obligo, que ella tenia su DNI, su celular nadie le quito y podía usar en cualquier momento. El investigado menciono que es solamente es cajero, un trabajador más, que viene trabajando recién un mes, que apenas conoce a la supuesta agraviada, el efectivo menciono que solamente hace su trabajo en la intervención, en los actos para preparar el informe policial bajo conducción del Fiscal director de la investigación. La defensa técnica indico que hizo bien su trabajo en favor de su cliente el 
investigado, el Fiscal menciona que falta colaboración de la victima y el Juez solo se limitó a decir que administra justicia conforme a la ley valorando la prueba en forma conjunta , con sana critica, el defensor de la víctima señalo que debe haber jueces especializado en trata de personas, y que los fiscales necesitan más apoyo logístico, y que falta repotenciar centros de protección y cuidados de la agraviada, los abogados defensores de los investigados dijeron que dichos hechos denunciados no constituían trata de personas, que hay insuficiencia probatoria, que la declaración de la victima no es clara, es poco confusa, que no hay imputación necesaria y que la fiscalía no logro a probar su imputación inicial. Se concluye que en los actos iniciales desde la intervención policial a los investigados por trata de personas se presenta mucho ruido despliegue de personal policial, fiscal, e incluso judicial, posteriormente va perdiendo vigencia o cierto agotamiento.

\section{DISCUSION DE LOS RESULTADOS / CONCLUSIONES}

Los hallazgos es que la culminación de un proceso judicial penal por trata de personas en sede judicial - concluyendo a favor del investigado no guarda coherencia con el inicio de la denuncia penal por trata de personas a cargo de la policía especializada de trata de personas y fiscalía especializada, iniciando contra los intervenidos, las causas que originan este fenómeno son la aparición de nuevas pruebas que van desvaneciendo la tesis de cargo inicial, y declaración en sede fiscal o judicial no tan clara, dejando vacíos y fundamentalmente la declaración de la supuesta agraviada que no da mayores luces- aportes de cargo, esto se debe a su propia experiencia, a su misma declaración en libre albedrio no sindica directamente a su tratante; pero revisando la teoría de las naciones unidas contra la droga y el delito- UNOCD -2019 señalaron en su obra las dificultades del proceso judicial se debe a la no declaración de la agraviada en contra de su tratante por miedo. Interpreté el resultado que no guarda relacion entre la pomposa propaganda de ONGs en contra la trata de personas, con los resultados judiciales en la praxis judicial del día a día. La conclusión de esta investigación desde la praxis judicial, no guarda coherencia con la investigación de Zhulali de Andrés (2017) en el sentido que ella afirma que la trata de personas es delito de lesa humanidad, que en teoría suena bonito, en la práctica es diferente. Para efectos de este estudio descriptivo y exploratorio es suficiente el enfoque cualitativo, y el método inductivo usado, a partir de este aporte en el conocimiento considero que van a surgir nuevas investigaciones desde la otra orilla es decir desde la realidad de los hechos judiciales.

\section{REFERENCIAS}

Abdulkareem, SH (2021). Supervisión del Consejo de Seguridad sobre las violaciones estatales del derecho internacional sobre la trata de personas (Revisión del tema). Ilkogretim Online , 20 (6), 603-607. https://doi.org/10.17051/ilkonline.2021.06.064

Alarcón, M (2018) Ilícitos penales derivados de la minería ilegal de oro en el Perú. caso Madre de Dios M+A, revista electrónica de medioambiente, ISSN- e1886- 3329.

Arana, E (2015) Algunos criterios del concepto de trata de personas. Revista VERBA IURIS 34. https://revistas.unilibre.edu.co/index.php/verbaiuris/article/view/13/11.

Barbuzano, E., Antolínez I., \& Alonso, A. (2020). ¿Pueden hablar las «víctimas» de trata? Una etnografía multisituada sobre la construcción del silencio y su confrontación en la trata de mujeres nigerianas con fines de explotación sexual. AIBR. Revista de Antropología Iberoamericana, 15(3), 463-489. https://doi.org/10.11156/aibr.150303

Blanco, C., \& Marinelli, C. (2017). Víctimas de trata de personas versus migrantes en situación irregular. Retos y lineamientos para la atención y protección de las víctimas de trata de personas extranjeras en el Perú. Derecho PUCP, 78, 173- 198. https://doi.org/10.18800/derechopucp.201701.007

CHS Alternativo (2014). Trata de personas ¿Qué pasa en las regiones del Perú? http://chsalternativo.org/wpcontent/uploads/2015/12/2014_que_pasa_en_las_regiones_prtg-1.pdf\#page=40

Código Penal, (1991). Código Penal Peruano actualizado. LP pasión por el derecho. https://lpderecho.pe/codigo-penalperuano-actualizado. 
Código Procesal Peruano (2004). Ministério de Justicia http://spij.minjus.gob.pe/content/publicaciones_oficiales/img/codigoprocesalpen al.pdf

Dammert-Guardia, M., Dammert, L., \& Sarmiento, K. (2020). La trata de personas en los Andes: dinámicas socioespaciales en las fronteras de Perú. Íconos. Revista de Ciencias Sociales, 68, 117-134. https://doi.org/10.17141/iconos.68.2020.4043

Defensoría del Pueblo (2017) PDF] Trata de personas con fines de explotación sexual en agravio de mujeres adultas. Estudio de casos en las regiones de Lima, Madre de Dios, Piura, Pasco.

Díaz, G. M. (2017). Trata de personas, tráfico de migrantes y la gobernabilidad de la migración a través del crimen. Etnográfica: Revista Do Centro de Estudos de Antropologia Social, 21(3), 541-554. https://doi.org/10.4000/etnografica.5026

Fuentes, A. (2018). «Tierra de nadie»: Estado y desarrollo humano en Madre de Dios. Debates En Sociología, 47, 157185. https://doi.org/10.18800/debatesensociologia.201802.006

Gobierno Regional del Madre de Dios, (2017). Plan Regional de

Acción contra la trata de personas Madre de Dios 2011-2016. Repositryoim.org h https://bit.ly/3shz1Tl

Hatfield, E. (2018). La Trata De Personas O La Industria Del Sexo a Través Del Cine Mexicano. Chasqui, $47(1), 144$.

INEI, (2019). Peru estadísticas de trata de personas 2012- 2019. https://www.inei.gob.pe/media/MenuRecursivo/boletines/boletin_trata_de_personas_4.pdf

Jaimes, J. R., Parra, J. V., \& Aceros, J. C. (2018). Análisis de las medidas de asistencia a víctimas de trata de personas en Colombia en perspectiva de derechos. https://doi.org/10.22395/ojum.v17n33a4

Jaris Mujica. (2016). Trabajo adolescente en la extracción de madera en la Amazonía peruana: explotación laboral, trabajo forzoso, trata de personas. Revista de Direitos e Garantias $\quad$ Fundamentais, 17(2), 155180. https://doi.org/10.18759/rdgf.v17i2.786

Ministerio Publico, (2019). Guía operativa para la investigación de los delitos de trata de personas.

Montoya (2016). El delito de trata de personas como delito complejo y sus dificultades en la legislación peruana.

Oficina de las Naciones Unidas contra la Droga y el Delito- UNOCD (2019), serie de módulos universitarios trata de personas, modulo nueve.

Ordinola M. (2019) Situación actual del delito de trata de personal en el Perú.

Pajon L. (2020). Towards an evidence-based investigation framework for human trafficking crimes. https://ethos.bl.uk/OrderDetails.do?uin=uk.bl.ethos.831765

Rodríguez-Fernández, A., \& Ramos-Con, P. (2018). Entre lo oculto y lo silenciado: la trata de personas en Costa Rica y sus desafíos para la investigación académica. (Spanish). Revista Espiga, 17(35), 18-30.

Tuesta, D. (2018). «Son prácticamente casos perdidos». Trata de personas y respuesta judicial en Madre de Dios, Perú. Debates En Sociología, 47, 73-99. https://doi.org/10.18800/debatesensociologia.201802.00

Vargas Parra, J., Reyes Jaimes, J., \& Chía Cifuentes, M. (2019). Indicadores para la medición de la respuesta de los estados en el abordaje de la trata de personas https://doi.org/10.29375/01240781.3596

Zhulali de Andrés (2017). Tesis doctoral Trata de Personas: Crimen de lesa humanidad. 